\title{
Educação permanente em saúde como dispositivo para transformação das práticas
}

\section{em saúde na atenção básica}

\author{
Permanent health education as a device for the transformation of health practices in basic care \\ La educación em salud permanente como dispositivo de transformación de prácticas de salud em la
} atención básica

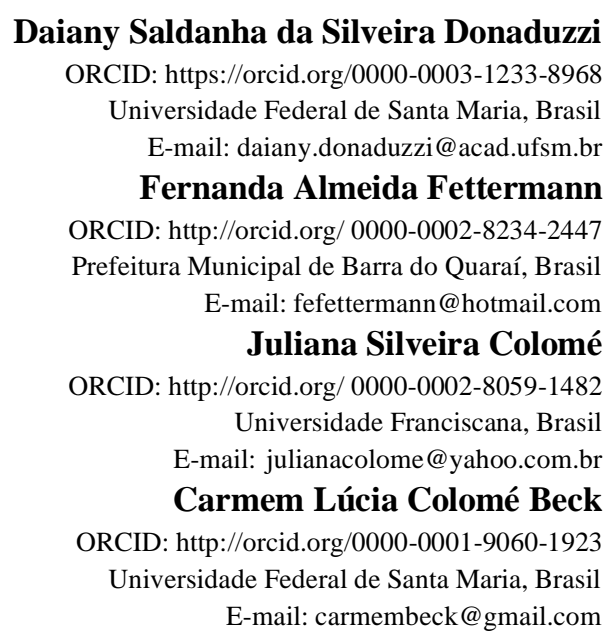

\begin{abstract}
Resumo
Este estudo teve como objetivo analisar as tendências das produções brasileiras, com base nas teses e dissertações, acerca da Educação Permanente em Saúde com trabalhadores da Atenção Básica. Trata-se de uma revisão narrativa, desenvolvida com teses e dissertações disponíveis no Catálogo de Teses e Dissertações da Coordenação de Aperfeiçoamento de Pessoal de Nível Superior. A busca foi realizada em dezembro de 2020, com a estratégia: "educação permanente em saúde" and "trabalhadores". Após aplicar os critérios de seleção, 24 produções compuseram o corpus deste estudo. A maioria dos estudos é proveniente de dissertações (87,5\%), com delineamento qualitativo (66,6\%), produzidos em instituições da Região Sudeste do Brasil (45\%). Evidenciaram-se estudos que investigaram, principalmente, o conceito de Educação Permanente em Saúde, destacando-se que há pouca clareza na diferenciação com os conceitos de educação continuada e educação em serviço, o que pode interferir na sua operacionalização e nos resultados junto aos trabalhadores, gestores e usuários. Também, se identificou que a Educação Permanente é uma estratégia potente para a transformação das práticas em saúde. Concluiu-se que a Educação Permanente mostrou-se como uma oportunidade de reflexão sobre o processo de trabalho em saúde, em que os sujeitos têm a possibilidade de se expressar, olhar para a própria prática e buscar novos saberes.
\end{abstract}

Palavras-chave: Educação permanente em saúde; Atenção Básica; Trabalhadores da saúde.

\begin{abstract}
This study aimed to analyze the trends of Brazilian productions, based on theses and dissertations, about Permanent Health Education with Primary Care workers. It is a narrative review, developed with theses and dissertations available in the Catalog of Theses and Dissertations of the Coordination for the Improvement of Higher Education Personnel. The search was carried out in December 2020, with the strategy: "permanent health education" and "workers". After applying the selection criteria, 24 productions made up the corpus of this study. Most studies come from dissertations (87.5\%), with a qualitative design (66.6\%), produced in institutions in the Southeast Region of Brazil (45\%). Studies that investigated, mainly, the concept of Permanent Education in Health were evidenced, emphasizing that there is little clarity in the differentiation with the concepts of continuing education and education in service, which can interfere in its operationalization and in the results with the workers , managers and users. Also, it was identified that Permanent Education is a powerful strategy for the transformation of health practices. It was concluded that Permanent Education was shown as an opportunity for reflection on the health work process, in which the subjects have the possibility to express themselves, look at their own practice and seek new knowledge.
\end{abstract}

Keywords: Permanent Health Education; Basic Attention; Health workers. 


\section{Resumen}

Este estudio tuvo como objetivo analizar las tendencias de las producciones brasileñas, a partir de tesis y disertaciones, sobre Educación Permanente en Salud con trabajadores de Atención Primaria. Se trata de una revisión narrativa, desarrollada con tesis y disertaciones disponibles en el Catálogo de Tesis y Disertaciones de la Coordinación para el Perfeccionamiento del Personal de Educación Superior. La búsqueda se realizó en diciembre de 2020, con la estrategia: "educación permanente en salud" y "trabajadores". Después de aplicar los criterios de selección, 24 producciones conformaron el corpus de este estudio. La mayoría de los estudios son de disertaciones $(87,5 \%)$, con un diseño cualitativo $(66,6 \%)$, producidas en instituciones de la Región Sudeste de Brasil (45\%). Se evidenciaron estudios que investigaron, principalmente, el concepto de Educación Permanente en Salud, destacando que existe poca claridad en la diferenciación con los conceptos de educación continua y educación en servicio, lo que puede interferir en su operacionalización y en los resultados con los trabajadores. , gestores y usuarios. Asimismo, se identificó que la Educación Permanente es una poderosa estrategia para la transformación de las prácticas de salud. Se concluyó que la Educación Permanente se mostró como una oportunidad de reflexión sobre el proceso de trabajo en salud, en la que los sujetos tienen la posibilidad de expresarse, mirar su propia práctica y buscar nuevos conocimientos.

Palabras clave: Educación Sanitária Permanente; Atención básica; Trabajadores de la salud.

\section{Introdução}

O Sistema Único de Saúde (SUS) tem como competência ordenar a formação dos profissionais da área. Com isso, o Ministério da Saúde criou em 2004, a Política Nacional de Educação Permanente em Saúde (PNEPS) instituída por meio da Portaria GM/MS nº 198/2004 com objetivo de desencadear mudanças no processo de educação dos profissionais da saúde, ao formar trabalhadores da saúde para atender às reais necessidades de saúde da população (Brasil, 2004b).

A Educação Permanente em Saúde (EPS) é um conceito pedagógico, definida como aprendizagem no trabalho, onde o aprender e o ensinar se incorporam ao cotidiano das organizações e ao trabalho. Está ancorada na aprendizagem significativa e na possibilidade de transformar as práticas profissionais (BRASIL, 2018). Está atrelada à (re)significação do processo de trabalho, sendo o cenário dos serviços de saúde a principal fonte de conhecimento, a qual pode oferecer reflexões e possibilidades de problematização da realidade dos mesmos (D’Avila et al., 2014).

A Educação Continuada, por sua vez, tem como objetivo atualizar conhecimentos técnico-científicos, a partir da utilização de pedagogias de transmissão de conhecimento (Ceccim, 2004). Contudo, diante da complexidade dos processos de trabalho em saúde, é considerada insuficiente para atender às demandas da Atenção Básica (AB) pela sua desarticulação com as práticas de atenção à saúde.

No contexto da $\mathrm{AB}$, a participação ativa dos trabalhadores em espaços coletivos de aprendizagem é fundamental para a efetividade dos serviços, aprimoramento e revitalização do processo de trabalho tendo em vista a qualificação da atenção em saúde (Paschoal; Mantovani; Méier, 2007).

Nessa perspectiva, a identificação das produções científicas brasileiras, proposta neste estudo, forneceu um importante levantamento dos aspectos relevantes da EPS, identificando lacunas do conhecimento, com vistas a propor novos estudos. A partir disso, objetivou-se analisar as tendências das produções brasileiras acerca da Educação Permanente em Saúde com trabalhadores da Atenção Básica, com base nas teses e dissertações disponibilizadas pelo Catálogo de Teses e Dissertações da Coordenação de Aperfeiçoamento de Pessoal de Nível Superior.

\section{Metodologia}

Trata-se de uma revisão narrativa de literatura (Rother, 2007), desenvolvida por meio da análise de teses e dissertações brasileiras. O estudo foi desenvolvido a partir da questão de revisão: "Quais as tendências das produções brasileiras de teses e dissertações acerca da educação permanente em saúde com trabalhadores da Atenção Básica?’. 
Para isso, realizou-se uma busca no Catálogo de Teses e Dissertações da Coordenação de Aperfeiçoamento de Pessoal de Nível Superior (CAPES), no mês de dezembro de 2020. Definiram-se como estratégia de busca avançada os termos "educação permanente em saúde" and "trabalhadores", não sendo estabelecido recorte temporal.

Como critérios de inclusão, os estudos precisavam abordar a temática educação permanente no âmbito da Atenção Básica e estarem disponíveis on-line e na íntegra. Em relação aos estudos que não estavam disponíveis no Catálogo de Tese e Dissertações, buscou-se a seleção na biblioteca de origem e na ferramenta Google. Nessas condições, o estudo não sendo encontrado, era excluído do corpus da revisão.

Conforme os critérios de seleção, procedeu-se inicialmente à leitura dos títulos e após dos resumos das produções, conforme exemplificado na figura abaixo (Figura 1).

Figura 1: Fluxograma de seleção das produções para compor o corpus deste estudo.

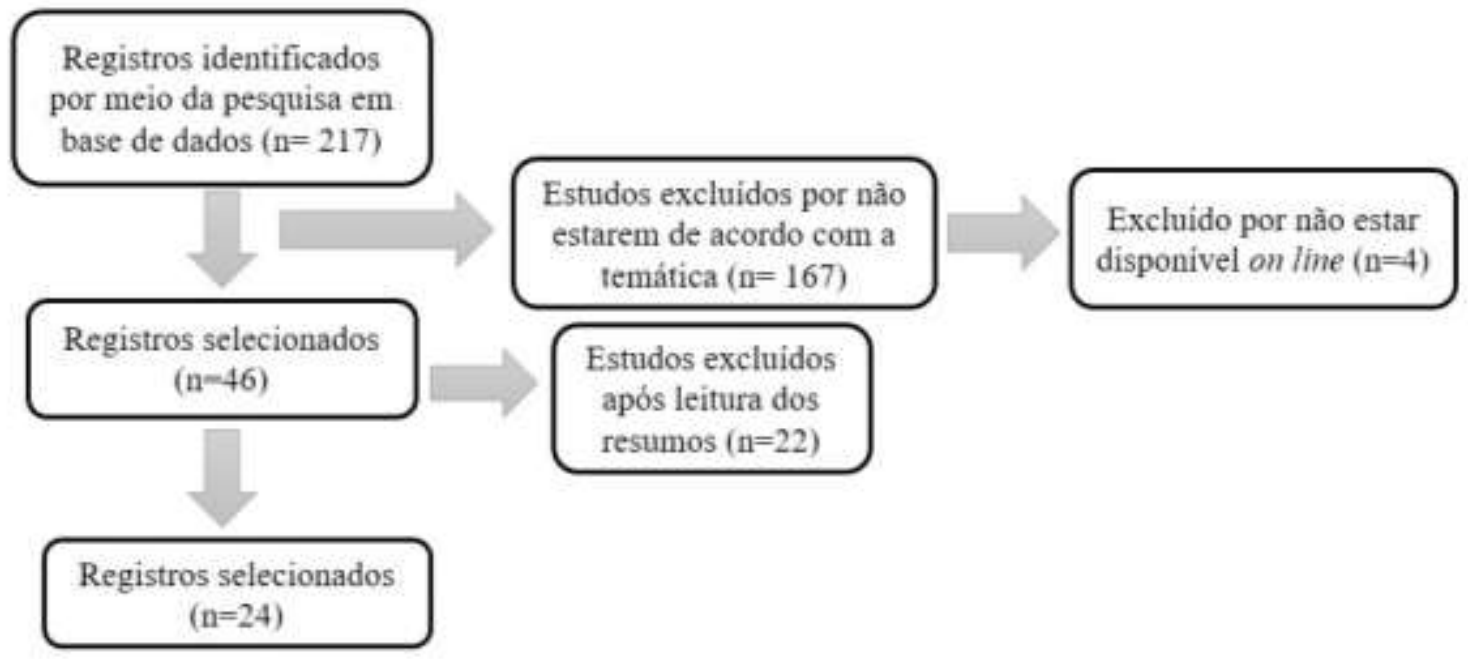

Fonte: Autores.

Observou-se que dos 217 estudos encontrados, 167 foram excluídos visto que não abordavam a temática em questão e 04 por não estarem disponíveis on-line na íntegra. Dos 46 estudos selecionados para leitura dos resumos, foram excluídos 22 não respondiam à questão de pesquisa. Sendo assim, o corpus da revisão foi de 24 estudos (Figura 1).

Após a seleção dos estudos, realizou-se uma leitura crítica. Para a organização e compreensão das produções selecionadas, desenvolveu-se uma ficha para a extração das seguintes informações: tipo de estudo (teses ou dissertações); local de origem dos estudos; região do país; ano de publicação; tipo de abordagem e principais resultados.

Realizou-se a análise dos resultados de maneira descritiva por meio de frequências absolutas (n) e relativas (\%). Os dados obtidos permitiram a construção de duas categorias, quais sejam: Concepções de educação permanente, educação continuada e educação em serviço; Educação permanente em saúde: estratégia de transformação das práticas em saúde.

\section{Resultados e Discussão}

Dentre as 24 produções incluídas (Tabela 1), três (12,5\%) eram teses e 21 (87,5\%) eram dissertações. As pesquisas foram desenvolvidas em 13 universidades brasileiras, sendo na sua maioria, pela Universidade Federal Fluminense, com 06 estudos (25\%), seguida da Universidade de São Paulo com 4 estudos (16,66\%). 
No que se refere à região, houve predomínio da região Sudeste com 18 produções (75\%), seguida da Nordeste $(29,16 \%)$. Essa questão pode estar relacionada à implementação do Programa de Educação Permanente para médicos de Saúde da Família em São Paulo/SP, região onde se concentraram a maior parte dos estudos $(45,83 \%)$.

Quanto ao ano de publicação observou-se que o um estudo foi publicado em 2006 (Vieira, 2006), sendo o período de maior concentração entre os anos de 2014 (Figueiredo, 2014; Chagas, 2014; Bruno, 2014; Pereira, 2014; Lopes, 2014), 2015 (Alcântara, 2015; Araújo, 2015; Aiub,2015; Lima, 2015; e 2017 (Oliveira, 2017; Ruback, 2017; Terraza, 2017; Dorneles, 2017; Lecca, 2017).Pode haver uma tendência ao aumento de publicações a partir da criação da Portaria no 3.194/17, que instituiu o Programa para o Fortalecimento das Práticas de Educação Permanente em Saúde no SUS (Brasil, 2018). Esse programa tem por finalidade promover a formação e desenvolvimento dos trabalhadores, a partir dos problemas cotidianos referentes à atenção à saúde e à organização do trabalho em saúde no âmbito do SUS. Também, o fortalecimento das práticas de EPS nos estados, Distrito Federal e municípios, com o objetivo de fortalecer a qualificação dos profissionais de saúde (Brasil, 2018).

Quanto ao tipo de abordagem, a abordagem qualitativa esteve presente em 16 estudos (66,66\%), seguida de quatro estudos com abordagem quantitativa $(16,66 \%)$ e quatro qualitativa-quantitativa $(16,66 \%)$. A abordagem qualitativa permite aliar a questão do significado e da intencionalidade como inerente aos atos, às relações e estruturas sociais, no contexto em que o objeto de estudo se encontra inserido (Minayo, 2014).

Tabela 1: Seleção de Dissertações e Teses brasileiras que abordam a Educação Permanente em Saúde com Trabalhadores da Atenção Primária à Saúde.

\begin{tabular}{|c|c|c|c|}
\hline REFERÊNCIA & INSTITUIÇÃO & MÉTODO & PRINCIPAIS ACHADOS NOS ESTUDOS \\
\hline (Vieira, 2006) & $\begin{array}{l}\text { Universidade Estadual } \\
\text { de Montes Claros- } \\
\text { Unimontes. }\end{array}$ & Abordagem qualitativa & $\begin{array}{l}\text { Formação em serviço integrada ao processo } \\
\text { educativo e as práticas de saúde, desenvolvida de } \\
\text { forma incipiente e não sistematizada. Constatou, } \\
\text { ainda, o desenvolvimento de treinamentos e } \\
\text { capacitações para atualização dos trabalhadores, que } \\
\text { se caracterizavam por utilizar metodologias } \\
\text { tradicionais desvinculados das práticas concretas das } \\
\text { Unidades de Saúde. }\end{array}$ \\
\hline (Silva, 2009) & $\begin{array}{l}\text { Escola de } \\
\text { Enfermagem da USP }\end{array}$ & $\begin{array}{l}\text { Estudo descritivo, } \\
\text { transversal, com análise } \\
\text { quantitativa e qualitativa. }\end{array}$ & $\begin{array}{l}\text { É necessário ocorrer esclarecimentos conceituais e } \\
\text { operacionais sobre EPS. É preciso haver uma equipe } \\
\text { gestora com habilidade para identificar os nós críticos } \\
\text { e disponibilidade de realizar um planejamento } \\
\text { estratégico voltado à assistência da ESF. }\end{array}$ \\
\hline (Oliveira, 2017) & $\begin{array}{l}\text { Escola Paulista de } \\
\text { Enfermagem- } \\
\text { UNIFESP }\end{array}$ & $\begin{array}{l}\text { Abordagem qualitativa } \\
\text { segundo referencial } \\
\text { teórico de Análise } \\
\text { situacional. }\end{array}$ & $\begin{array}{l}\text { O trabalho cotidiano dos profissionais da ESF é } \\
\text { carregado de afeto, subjetividade, complexidade e } \\
\text { vida. Por isso, os profissionais precisam ter espaços } \\
\text { criativos com discussões que possibilitem a análise de } \\
\text { suas implicações e reflexões acerca da vida e do } \\
\text { mundo do trabalho em saúde. }\end{array}$ \\
\hline (Alcântara, 2015) & $\begin{array}{l}\text { Escola Paulista de } \\
\text { Enfermagem- } \\
\text { UNIFESP }\end{array}$ & Pesquisa-intervenção & $\begin{array}{l}\text { A EPS possibilita delicadas transformações quanto ao } \\
\text { trabalho em saúde das equipes. Representa um espaço } \\
\text { que cria uma potência de escutar, reconhecer e } \\
\text { investigar situações trazidas pelo trabalhador, e como } \\
\text { oportunidade de "cuidar de quem cuida" no cotidiano } \\
\text { do trabalho. }\end{array}$ \\
\hline (Pinto, 2011) & $\begin{array}{l}\text { Universidade Federal } \\
\text { de São Carlos - } \\
\text { UFSCar }\end{array}$ & Abordagem qualitativa & $\begin{array}{l}\text { O processo educativo não coaduna com a EPS. As } \\
\text { ações educativas reproduzem a transmissão vertical } \\
\text { de conhecimentos (educação bancária) e privilegia } \\
\text { conteúdos técnicos que não dão respostas às práticas } \\
\text { em saúde. Há desconhecimento do conceito de EPS. }\end{array}$ \\
\hline
\end{tabular}




\begin{tabular}{|c|c|c|c|}
\hline (Figueiredo, 2014) & $\begin{array}{l}\text { Universidade Federal } \\
\text { Fluminense-UFF }\end{array}$ & Pesquisa-ação & $\begin{array}{l}\text { A EPS é pouco abordada no movimento institucional, } \\
\text { sendo a capacitação predominante. Contudo, a EPS é } \\
\text { almejada tanto por gestores, como por trabalhadores } \\
\text { na perspectiva de melhoria do SUS. O poder de } \\
\text { resolução de conflitos foi atribuído pelos gestores à } \\
\text { EPS no processo de condução do sistema, pois é um } \\
\text { dispositivo com capacidade de romper com o } \\
\text { instituído, provocar no trabalhador a reflexão de sua } \\
\text { prática. }\end{array}$ \\
\hline (Chagas, 2014) & $\begin{array}{l}\text { Universidade Federal } \\
\text { Fluminense-UFF }\end{array}$ & Abordagem qualitativa & $\begin{array}{l}\text { O trabalho, no plano da micropolítica, funciona como } \\
\text { um dispositivo de EPS porque revela as linhas que } \\
\text { atuam com objetivo de capturar o trabalho vivo dos } \\
\text { trabalhadores a serviço dos saberes e poderes } \\
\text { constituídos, ao mesmo tempo em que revela os } \\
\text { fluxos que, não podendo ser determinados } \\
\text { previamente, operam por outras lógicas. }\end{array}$ \\
\hline (Bruno, 2014) & $\begin{array}{l}\text { Universidade Federal } \\
\text { Fluminense-UFF }\end{array}$ & $\begin{array}{l}\text { Abordagem qualitativa, } \\
\text { do tipo pesquisa-ação. }\end{array}$ & $\begin{array}{l}\text { A EPS demonstra potência e influência como } \\
\text { dispositivo indutor da construção de estratégias de } \\
\text { enfrentamento dos desastres naturais, pois instiga, } \\
\text { permite e facilita a expressão dos sujeitos, fazendo } \\
\text { com que os mesmos reflitam sobre as próprias } \\
\text { práticas e proponham novas formas de trabalho indo } \\
\text { ao encontro com as premissas e objetivos da Política } \\
\text { Nacional de EPS. }\end{array}$ \\
\hline (Araújo, 2015) & $\begin{array}{l}\text { Universidade Estadual } \\
\text { de Feira de Santana- } \\
\text { UEFS }\end{array}$ & $\begin{array}{l}\text { Qualitativa de abordagem } \\
\text { crítico analítica, numa } \\
\text { perspectiva aproximada } \\
\text { do método Dialético. }\end{array}$ & $\begin{array}{l}\text { A EPS está associada para os trabalhadores à } \\
\text { capacitação e atualização dos conhecimentos; para os } \\
\text { gestores é entendida como um processo de reflexão } \\
\text { das práticas para a sua transformação. Desafios: } \\
\text { rotatividade profissional; falta de profissionais com o } \\
\text { perfil adequado para atuarem na Atenção Básica; } \\
\text { falta de materiais para realização das atividades; e a } \\
\text { EPS não ser vista como prioridade pela gestão. A } \\
\text { EPS permite que os trabalhadores de saúde } \\
\text { desenvolvam ações de produção do cuidado com } \\
\text { maior resolubilidade. }\end{array}$ \\
\hline (Ruback, 2017) & $\begin{array}{l}\text { Universidade Federal } \\
\text { Fluminense-UFF }\end{array}$ & $\begin{array}{l}\text { Abordagem qualitativo - } \\
\text { cartográfico }\end{array}$ & $\begin{array}{l}\text { Para se produzir aprendizagens todos os lugares são } \\
\text { possíveis, em todos os encontros, nos seus fazeres } \\
\text { cotidianos. A EPS propicia a condução dos casos, o } \\
\text { compartilhamento de sentidos, o olhar, a escuta, no } \\
\text { cotidiano. Quem colabora nesta aprendizagem de } \\
\text { pensar as práticas de cuidado em saúde não é apenas } \\
\text { a técnica, mas as singularidades de cada um. }\end{array}$ \\
\hline (Terraza, 2017) & $\begin{array}{l}\text { Universidade de São } \\
\text { Paulo- USP }\end{array}$ & Abordagem qualitativa & $\begin{array}{l}\text { As ações de EPS, realizadas com os trabalhadores da } \\
\text { APS são práticas educativas baseadas nos conceitos } \\
\text { da Educação Continuada e Educação em Serviço. As } \\
\text { metodologias adotadas são as mesmas dos processos } \\
\text { de formação inicial e, por isso, não existe a } \\
\text { participação do trabalhador. As ações educativas são } \\
\text { feitas por categorias profissionais, e não são } \\
\text { abordados temas relacionados aos saberes da prática. } \\
\text { A EPS é uma prática ainda distante da proposta da } \\
\text { Política Nacional de NEPS. }\end{array}$ \\
\hline (Dorneles, 2017) & $\begin{array}{l}\text { Universidade de São } \\
\text { Paulo-USP }\end{array}$ & Abordagem qualitativa & $\begin{array}{l}\text { O recurso tecnológico é relevante e adequado para } \\
\text { agregar conhecimento sobre a EPS e pode ser } \\
\text { utilizado em diversos contextos. A construção do } \\
\text { infográfico animado confere sustentação acadêmica e } \\
\text { científica ao produto construído como tecnologia de } \\
\text { informação e comunicação, e indica a possibilidade } \\
\text { do seu potencial pedagógico enquanto um recurso } \\
\text { computacional que pode favorecer a aprendizagem } \\
\text { significativa sobre EPS e contribuir para a } \\
\text { transformação das práticas de saúde. }\end{array}$ \\
\hline
\end{tabular}




\begin{tabular}{|c|c|c|c|}
\hline (Sena, 2014) & $\begin{array}{l}\text { Fundação Osvaldo } \\
\text { Cruz-FIOCRUZ }\end{array}$ & $\begin{array}{l}\text { Abordagem quantitativa - } \\
\text { intervenção }\end{array}$ & $\begin{array}{l}\text { A EPS é uma ferramenta importante para a } \\
\text { aquisição/atualização de conteúdos, pois os } \\
\text { trabalhadores aprimoram e/ou aumentam seus } \\
\text { conhecimentos sobre a ESF. }\end{array}$ \\
\hline (Marques, 2016) & $\begin{array}{l}\text { Universidade Federal } \\
\text { de Alagoas-UFAL }\end{array}$ & $\begin{array}{l}\text { Abordagem qualitativa, } \\
\text { investigação exploratória. }\end{array}$ & $\begin{array}{l}\text { A EPS apresenta-se ora como sinônimo de Educação } \\
\text { Continuada, ora como repasse de conhecimentos para } \\
\text { a população e ora sinalizando a EPS como ação- } \\
\text { reflexão-ação; vinculam-se as práticas de EPS } \\
\text { desenvolvidas nos serviços a reuniões de equipe, } \\
\text { grupos educativos em saúde e participação em } \\
\text { eventos científicos. Percebem a EPS como } \\
\text { fortalecimento do trabalho em equipe, o cuidado de si } \\
\text { e o Apoio Matricial na Atenção Básica. }\end{array}$ \\
\hline (Alves, 2010) & $\begin{array}{l}\text { Universidade Estadual } \\
\text { de Feira de Santana - } \\
\text { UEFS }\end{array}$ & Abordagem qualitativa & $\begin{array}{l}\text { A EPS revela-se como uma potência a ser explorada } \\
\text { na valorização do trabalhador do SUS, bem como um } \\
\text { dispositivo na qualificação de seu trabalho, podendo } \\
\text { ser contraponto para qualificar a gestão do trabalho, } \\
\text { cujo desafio é a construção de sujeitos que se sintam } \\
\text { parte de um sistema integral. }\end{array}$ \\
\hline (Pereira, 2014) & $\begin{array}{l}\text { Instituto Sírio Libanês } \\
\text { de Ensino e Pesquisa }\end{array}$ & $\begin{array}{l}\text { Abordagem qualitativa, } \\
\text { investigação exploratória } \\
\text { e descritivo-analítica. }\end{array}$ & $\begin{array}{l}\text { A EPS para os gestores foi referida como um desafio } \\
\text { de formação e educação em serviço. Os demais } \\
\text { trabalhadores destacaram que na prática há } \\
\text { multiplicidade de traduções da Educação Permanente; } \\
\text { e que os encontros produzem desafios e conquistas na } \\
\text { organização do trabalho. O conjunto dos elementos } \\
\text { facilitadores e limitantes na implantação da EPS } \\
\text { indicam potenciais transformações das práticas com } \\
\text { vistas à ampliação de impacto no uso deste } \\
\text { dispositivo de gestão e de educação na saúde. }\end{array}$ \\
\hline (Lecca, 2017) & $\begin{array}{l}\text { Universidade de São } \\
\text { Paulo-USP }\end{array}$ & $\begin{array}{l}\text { Pesquisa-ação, com } \\
\text { abordagens quantitativa e } \\
\text { qualitativa. }\end{array}$ & $\begin{array}{l}\text { A realização e a avaliação do programa educativo } \\
\text { incitaram importantes reflexões sobre o cotidiano do } \\
\text { trabalho, pois partiu de problemas reais da prática, na } \\
\text { perspectiva da aprendizagem significativa e dos } \\
\text { pressupostos da Política Nacional de EPS. }\end{array}$ \\
\hline (Aiub, 2015) & $\begin{array}{l}\text { Universidade de São } \\
\text { Paulo -USP }\end{array}$ & & $\begin{array}{l}\text { Há uma confusão de conceitos de Educação } \\
\text { continuada como sendo EPS. Considerada como } \\
\text { maneira de fazer da reflexão uma via de } \\
\text { melhoramento do serviço e fortalecimento da } \\
\text { Atenção Básica. É uma maneira de manejar as } \\
\text { relações na equipe, na busca de torna-la mais coesa e } \\
\text { como meio de valorizar e motivar os profissionais. } \\
\text { EPS como forma de levar à corresponsabilização do } \\
\text { cuidado e o respeito com os saberes do próximo, no } \\
\text { sentido da tomada de decisões, também vista como } \\
\text { maneira de qualificar o vínculo. }\end{array}$ \\
\hline (Lopes, 2014) & $\begin{array}{l}\text { Universidade Federal } \\
\text { Fluminense-UFF }\end{array}$ & $\begin{array}{l}\text { Pesquisa descritiva de } \\
\text { abordagem } \\
\text { quantiqualitativa e com } \\
\text { proposta de pesquisa } \\
\text { ação. }\end{array}$ & $\begin{array}{l}\text { A EPS, a Educação Continuada em Saúde e a } \\
\text { Educação Popular em Saúde eram tratadas como } \\
\text { sinônimas e não tinham os seus pressupostos } \\
\text { definidos de forma clara. As principais dificuldades } \\
\text { apontadas foram às condições de trabalho precárias e } \\
\text { a falta de incentivo da gestão para as atividades de } \\
\text { EPS. Como facilidades, foram as atividades de } \\
\text { educação em saúde ser realizadas de acordo com o } \\
\text { cotidiano de trabalho e o potencial a partir da } \\
\text { discussão crítica que possibilita às equipes } \\
\text { elaborarem suas linhas de cuidado na lógica do } \\
\text { sujeito. }\end{array}$ \\
\hline (Almeida, 2016) & $\begin{array}{l}\text { Universidade Federal } \\
\text { do Ceará-UFC }\end{array}$ & $\begin{array}{l}\text { Estudo descritivo, } \\
\text { observacional, transversal } \\
\text { e quali-quantitativo. }\end{array}$ & $\begin{array}{l}\text { A Política Nacional de EPS é conhecida por } 19,2 \% \\
\text { dos cirurgiões-dentistas, } 29,5 \% \text { dos médicos e } 45,1 \% \\
\text { dos enfermeiros. Quanto aos dados qualitativos, } \\
\text { destaca-se: aprendizagem significativa,trabalho em } \\
\text { equipe, tecnologias digitais de informação e }\end{array}$ \\
\hline
\end{tabular}




\begin{tabular}{|c|c|c|c|}
\hline & & & $\begin{array}{l}\text { comunicação e necessidade de EPS. A aprendizagem } \\
\text { no e para o serviço, realizada de forma } \\
\text { multiprofissional, contribui para a qualificação e } \\
\text { fortalecimento do SUS. }\end{array}$ \\
\hline (Campos, 2018) & $\begin{array}{l}\text { Universidade Federal } \\
\text { de Minas Gerais- } \\
\text { UFMG }\end{array}$ & Abordagem qualitativa & $\begin{array}{l}\text { A EPS é reconhecida nas reuniões de equipe e de } \\
\text { matriciamento, nas trocas de saberes e experiências } \\
\text { em função da resolução dos problemas de saúde da } \\
\text { população, reveladas por um discurso marcado por } \\
\text { coesão, metáforas, temporalidades, modalizações e } \\
\text { avaliações valorativas positivas e negativas acerca da } \\
\text { EPS. Evidenciaram-se forças potencias para } \\
\text { colaborar na mudança de modelo assistencial na } \\
\text { busca pela centralidade dos usuários na atenção à } \\
\text { saúde e a priorização das tecnologias leves. }\end{array}$ \\
\hline (Lima, 2015) & $\begin{array}{l}\text { Universidade Federal } \\
\text { de Rondônia-UNIR }\end{array}$ & $\begin{array}{l}\text { Estudo de caso de } \\
\text { abordagem qualitativa }\end{array}$ & $\begin{array}{l}\text { Há confusão no uso dos termos entre EPS, educação } \\
\text { em saúde e educação continuada. Alguns } \\
\text { trabalhadores concebem a EPS como dispositivo de } \\
\text { mudança no processo de trabalho e qualificação dos } \\
\text { serviços, contudo mantém uma prática distante do } \\
\text { discurso pelo despreparo para utilizarem EPS em seu } \\
\text { processo de trabalho. }\end{array}$ \\
\hline (Maciel, 2016) & $\begin{array}{l}\text { Universidade Federal } \\
\text { do Ceará-UFC }\end{array}$ & $\begin{array}{l}\text { Abordagem qualitativa do } \\
\text { tipo estudo de caso }\end{array}$ & $\begin{array}{l}\text { Há necessidade de ampliação do conceito de EPS e } \\
\text { de vivenciar outros espaços de aprendizagem, } \\
\text { especialmente a interiorização para o campo de } \\
\text { práticas no território. Políticas de gestão do trabalho e } \\
\text { da educação na saúde com ênfase na valorização } \\
\text { profissional e fortalecimento dos vínculos } \\
\text { constituem-se ferramentas que permitem o diálogo e } \\
\text { participação dos envolvidos no processo educativo, } \\
\text { de forma a alcançar o desenvolvimento de } \\
\text { habilidades e competências através da dissipação de } \\
\text { conhecimento. }\end{array}$ \\
\hline (Fried, 2018) & $\begin{array}{l}\text { Universidade Federal } \\
\text { Fluminense-UFF }\end{array}$ & $\begin{array}{l}\text { Qualitativa, descritiva e } \\
\text { exploratória, do tipo } \\
\text { Estudo de Caso }\end{array}$ & $\begin{array}{l}\text { Utilização da educação permanente como um } \\
\text { dispositivo pedagógico, por tomar como objeto a } \\
\text { reorganização da demanda, através da aprendizagem } \\
\text { inventiva na micropolítica do trabalho em um serviço } \\
\text { de saúde da família. }\end{array}$ \\
\hline
\end{tabular}

Fonte: Autores.

A partir da análise dos resultados encontrados, foram construídas duas categorias, quais sejam: Concepções de educação permanente, educação continuada e educação em serviço e Educação permanente em saúde: estratégia de transformação das práticas em saúde.

\section{Concepções de educação permanente, educação continuada e educação em serviço}

A tendência científica acerca da EPS com trabalhadores da Atenção Básica sinaliza a necessidade de esclarecimentos conceituais referente à educação permanente, a educação continuada e a educação em serviço, bem como em relação à sua operacionalização, tendo em vista o fortalecimento das práticas em saúde.

Há pouca clareza entre os conceitos de educação permanente, educação continuada, educação em serviço, utilizadas, na sua grande maioria, como sinônimos (Aiub, 2015; Lopes, 2014; Lima, 2015, Pinto, 2011).

Para Paschoal, Mantovani e Méier (2007), os três aspectos de educação têm caráter de continuidade do processo educativo, podendo levar o sujeito à transformação pessoal e profissional, incentivar o trabalhador para a transformação da sua prática, reduzindo as dificuldades também em relação ao ensino. 
Na percepção de Cotrim-Guimarães (2009), embora a Educação Permanente, a Educação Continuada e a Educação em Serviço tenham como proposta fortalecer o processo de trabalho e como ponto comum, promover a continuidade de ações educativas, estão fundamentadas em princípios metodológicos diferentes.

A EPS é uma política de saúde instituída pelo Ministério da Saúde por meio das Portarias no 198/2004 e nº 1.996/2007 (Brasil, 2004; Brasil, 2007). A EPS se sustenta na aprendizagem significativa, por meio do uso de metodologias ativas e de avanços científicos e tecnológicos. Esse tipo de educação está centrada no exercício cotidiano do trabalho, na articulação en tre os diferentes sujeitos em uma perspectiva multiprofissional e interdisciplinar (Ceccim; Feuerwerker, 2004). A EPS favorece a construção coletiva, sustentada pelo diálogo e reflexão sobre a prática, desenvolvimento dos trabalhadores, das organizações e, por conseguinte, impulsiona a melhoria da qualidade da assistência (Amestoy et al., 2008).

A educação continuada, por sua vez, tem como objetivo a qualificação, o aperfeiçoamento, a reciclagem, a aquisição de novos conceitos e da reformulação de práticas já existentes. Diferente da EPS, a educação continuada visa uma qualificação mais pontual, com vista sanar a necessidade de melhoria da prática por meio de atualizações (Saviani, 2008).

Nesse viés, a educação continuada envolve todas as ações educativas desenvolvidas após a formação, com a intenção de atualizar, aprimorar e adquirir conhecimentos, por meio de atividades que qualifiquem a competência do trabalhador e que esta esteja alinhada à suas responsabilidades (Dias et al.,2010).

Os estudos demonstram que a educação em serviço objetiva o desenvolvimento de capacidade cognitiva, psicomotora e relacional, contribuindo para a valorização profissional e institucional (Farah, 2003), sendo constituída por ações educativas no ambiente de trabalho que propicia ao profissional a capacidade de relacionar o que está sendo transmitido com sua prática diária (Paschoal, Mantovani e Meier; 2007). Para Bezerra (2003), a educação em serviço representa um meio para a aquisição de conhecimento, em que o trabalhador é capaz de alcançar o desenvolvimento pessoal e profissional, no contexto da realidade institucional e social.

A Educação em Serviço diz respeito às ações educativas desenvolvidas durante o processo de trabalho (Paschoal, 2004). É uma prática inerente ao processo de trabalho, composta por ações educativas no ambiente de trabalho para fazer com que o profissional consiga relacionar o que lhe está sendo transmitido a sua prática diária (Farah, 2003).

É notório que os conhecimentos e saberes tecnológicos na área da saúde se transformam rapidamente, exigindo dos trabalhadores uma atualização permanente, tendo em vista o seu desenvolvimento, bem como a adoção de estratégias de transformação das práticas de saúde. Para que um trabalhador incorpore novos elementos à sua prática e a seus conceitos, é necessário detectar os desconfortos experimentados no cotidiano do trabalho, perceber que seu fazer ou pensar é insuficiente ou insatisfatório para dar conta dos desafios do cenário do trabalho na atualidade. Após o desconforto ser percebido, surge a disposição para criar alternativas de práticas e de conceitos, para enfrentar o desafio de produzir transformações (Ceccim, 2005).

Constatou-se a operacionalidade da EPS por meio de metodologias tradicionais, não sistematizadas, no formato de capacitações, sustentadas pela transmissão vertical do conhecimento (Vieira, 2006; Silva, 2009). Nessa lógica, o trabalhador assume uma posição passiva para adquirir conteúdos a fim de manter-se atualizado (Sena, 2014), não propiciando respostas às práticas em saúde, uma vez que a metodologia tradicional o desvincula das práticas concretas (Araújo, 2015). Ainda, a EPS é entendida como um espaço de reunião ou mesmo participação em eventos científicos que priorizam categorias profissionais e não as equipes (Terraza, 2017).

A EPS não se define como um processo que ensina, mas que provoca o trabalhador da saúde a reconhecer o cenário de atuação como um disparador para a construção do conhecimento, possibilitando-o a reconhecer a si próprio. Nesse aspecto, se inserem as metodologias ativas, aproximando o trabalhador de situações reais, dinâmicas, criativas e inovadoras, levando ao distanciamento das estratégias educacionais propostas pelo ensino tradicional (Fernandes, 2019). 
Desse modo, percebe-se a necessidade de aprimoramento constante das metodologias ativas no cenário das organizações de saúde, para que estimulem o saber e o fazer crítico dos profissionais e o desenvolvimento de um cuidado qualificado e condizente com as demandas dos usuários dos serviços. As inquietações e os questionamentos no processo ensino-aprendizagem quebram as lógicas de ensino tradicional, ao despertar o senso crítico e promover a autonomia dos sujeitos envolvidos (Luz et al., 2020).

Destaca-se que muitos trabalhadores da saúde não assumem um protagonismo na resolução das questões do cotidiano do trabalho. Logo, a EPS surge como uma possibilidade e estratégia para incentivá-los a buscar a qualificação de seus processos de trabalho e a adotar uma atitude mais participativa, uma vez que a EPS, exige um questionamento permanente e compartilhado do processo de trabalho, com vistas à transformação das práticas em saúde (Rossetti et al., 2019).

No que se refere aos gestores em saúde, constatou-se que também não existem pressupostos teóricos definidos de forma clara, e a EPS está associada à formação e educação em serviço (Pereira, 2014), capacitação e atualização dos conhecimentos dos trabalhadores (Araújo, 2015). Embora não se defenda a ideia do pressuposto teórico certo e errado, reconhece-se na EPS, o poder de resolução de conflitos no processo de condução do sistema, pois é um dispositivo com capacidade de romper com o instituído, provocar no trabalhador a reflexão de sua prática (Figueiredo, 2014), capaz de desencadear um processo de reflexão das práticas para a sua transformação.

Sendo assim, entende-se que a educação permanente em saúde atende à complexidade dos processos de trabalho na Atenção Básica, sendo o cenário das práticas em saúde, disparadores para a mudança que se almeja, culminando em fortalecimento do cuidado ao usuário e do próprio trabalhador.

\section{Educação permanente em saúde: dispositivo de transformação das práticas em saúde}

Observou-se que o cotidiano dos trabalhadores da saúde é carregado de afeto, subjetividade, complexidade e vida (Oliveira, 2017). Nesse sentido, a EPS possibilita delicadas transformações quanto ao trabalho em saúde das equipes, pois representa um espaço que cria uma potência de escutar, reconhecer e investigar situações trazidas pelos próprios trabalhadores (Barbosa e Alcântara, 2015). Dessa forma, valoriza a condução dos casos por meio do compartilhamento de sentidos, do olhar, da escuta, valorizando a singularidade de cada sujeito (Ruback, 2017). Sendo assim, a EPS representa uma ferramenta importante para manejar as relações na equipe, torna-la mais coesa e como meio de valorizar e motivar os profissionais visto o respeito com o saberes do próximo, qualificando o vínculo (Aiub, 2015; Maciel, 2016).

A força de trabalho em saúde está diretamente relacionada com a garantia de acesso aos serviços de saúde de qualidade. A Organização Mundial da Saúde (OMS, 2013) destaca a importância da educação e formação contínua dos profissionais desta área, por meio de métodos eficazes. Da mesma forma, o SUS aponta para a transformação das práticas em saúde, a partir da aquisição de novos saberes pelos profissionais qualificados para abordar o processo saúde-doença de forma ampliada e humanizada.

Nesse sentido, A EPS invoca um novo pensar em saúde, permite reconhecer diferentes valores, saberes e desejos coletivos para entender o cotidiano das práticas em saúde, sendo este um espaço aberto à escuta, ao olhar diferenciado de cada trabalhador, ao diálogo criativo e à decodificação do processo de trabalho. Desse modo, é possível criar vínculos por meio da integração entre as equipes e a elaboração de estratégias apropriadas para o enfrentamento dos problemas (Ceccim, 2005).

Evidenciou-se que os profissionais precisam ter espaços criativos com discussões que possibilitem a análise de suas implicações e reflexões acerca da vida e do mundo do trabalho em saúde (Oliveira, 2017). Nesse viés, a EPS é entendida como um dispositivo com capacidade de romper com o instituído, permitir e facilitar a expressão dos sujeitos e provocar no 
trabalhador a reflexão de sua prática (Figueiredo, 2014), propondo novas formas de trabalho a partir dessas reflexões (Bruno, 2014).

O cotidiano das práticas em saúde é o cenário por excelência das interações, das ideias e dos ideais dos sujeitos. Nesse contexto, a mediação reflexiva entre os trabalhadores gera novas estratégias e novas invenções. Estratégias que reorganizam o caos, encontram recursos e desvios e enfrentam o imprevisto. Por meio da integração de saberes, nas diferenças e semelhanças entre cada sujeito e em cada experiência reflexiva, é que podem emergir estratégias e melhores práticas em saúde (Morin, 2002).

Nos processos de trabalho em saúde, as atividades educativas se estabelecem a todo o momento, seja com o usuário do serviço, seja entre os trabalhadores. Ao rejeitar essas relações e a subjetividade dos sujeitos por meio da ausência de espaços de aprendizagem protegidos que são essenciais no trabalho em saúde, é tolhida a liberdade, a criatividade, a vinculação, que impedem os trabalhadores de experimentar soluções para os problemas reais que atendam às necessidades, tanto dos usuários como dos trabalhadores (Brasil, 2007).

Outro panorama evidenciado foi com relação às políticas de gestão do trabalho e da educação na saúde com ênfase na valorização profissional, constituindo-se como ferramentas que permitem a participação dos envolvidos no processo educativo, de forma a alcançar o desenvolvimento de habilidades e competências por meio da dissipação de conhecimento (Maciel, 2016). O conjunto dos elementos facilitadores e limitantes na implantação da EPS indicam potenciais transformações das práticas (Bruno, 2014; Pereira, 2014) e sugerem indicativos para o desenvolvimento da Educação Permanente, com vistas à ampliação de impacto no uso deste dispositivo de gestão e de educação na saúde.

A gestão dos serviços considera a EPS como um espaço para a construção de um ambiente compartilhado de saberes e trocas de experiências que contribui, inclusive, para a resolução de conflitos (Figueiredo, 2014). Sendo assim, o trabalhador utiliza a EPS como um dispositivo na qualificação de seu trabalho, podendo ser contraponto para qualificar a gestão do trabalho, cujo desafio é a construção de sujeitos que se sintam parte de um sistema integral (Alves, 2010).

A educação permanente no âmbito do SUS se sustenta no compartilhamento de saberes, nas trocas de experiências e na participação dos sujeitos, cuja produção do conhecimento ocorre no cotidiano das instituições de saúde, tendo como base os problemas vivenciados por trabalhadores, gestores, usuários (Ceccim; Ferla, 2008). Logo, os trabalhadores, enquanto sujeitos reflexivos têm capacidade de propor soluções e inovações na assistência e gestão da saúde.

O Ministério da Saúde (MS) refere que o processo de formação dos trabalhadores da saúde deve ocorrer por meio da Educação Permanente, estruturada mediante a problematização do processo de trabalho, enquanto ferramenta de transformação de toda a rede de gestão e de serviços. A proposta é que o processo de qualificação dos trabalhadores por meio da 'aprendizagem no trabalho', enquanto dispositivo de gestão e educação em saúde, tenha como referência as necessidades de saúde dos usuários, da população, da gestão setorial e do controle social em saúde (Portaria n. 198/04, anexo II) (Brasil, 2004b). A EPS passa a ser vista como uma estratégia fundamental para a mudança no sistema de saúde e para a recomposição das práticas de formação, atenção, gestão, formulação de políticas e controle social no setor saúde (Duarte, 2012).

Nesse contexto de gestão e educação em saúde, também se inserem os processos de formação para a atuação profissional. Um dos obstáculos à mudança do modelo de atenção no SUS tem sido a formação dos profissionais para atuar no setor saúde (Campos, 2006). É urgente a necessidade de as instituições formadoras promoverem a ruptura com posicionamentos teóricos que desvinculam teoria e prática nos processos de formação para a atuação profissional, inserindo metodologias que promovam a reflexão sobre a realidade das práticas em saúde e os processos de trabalho (Macedo, Albuquerque, Medeiros; 2014).

O trabalho, no plano da micropolítica, funciona como um dispositivo de EPS porque revela as linhas que atuam com objetivo de capturar o trabalho vivo dos trabalhadores a serviço dos saberes e poderes constituídos, ao mesmo tempo em que 
revela os fluxos que, não podendo ser determinados previamente, operam por outras lógicas (Chagas, 2014; Fried, 2018). Evidenciaram-se esforços para contribuir na mudança de modelo assistencial, colocando o usuário como protagonista na atenção à saúde e a priorização das tecnologias leves (Campos, 2018).

A micropolítica está ancorada na lógica da mudança institucional e apresenta os conceitos de tecnologias: duras, leveduras e leves. As tecnologias duras se referem aos equipamentos tecnológicos tais como máquinas, normas e estruturas organizacionais. As tecnologias leve-duras estão pautadas nos saberes estruturados que atuam no processo de trabalho em saúde. As tecnologias leves permitem ao trabalhador adotar uma nova postura relacional com o usuário, por meio de um atendimento mais humanizado e comprometido. Da mesma forma, adotar uma nova postura frente à equipe, ocasionando bemestar (Merhy, 2002).

Quando se torna possível aplicar a vertente pedagógica da EPS em determinado cenário, estabelece-se um diálogo com a realidade do cotidiano do trabalho ou da formação em saúde, por meio de relações concretas que operam realidades e que possibilitam construir espaços coletivos que produzem um sentido nos atos produzidos no cotidiano do trabalhador (Ceccim, 2005).

Nesta transposição do trabalhador para a realidade em que estão inseridos, ocorre um sentimento de significação, um pensar não mais individual, mas coletivo, capaz de inventar formas de enfrentamentos coerentes com o seu contexto. Evidenciou-se a importância da aprendizagem significativa (Lecca, 2017; Almeida, 2016; Fried, 2018) como necessária para a EPS, pois valoriza a experiência cotidiana e considera que o pensamento surge a partir de uma situação vivida. Sendo assim, o aprender a aprender se incorpora à dinâmica da micropolítica do trabalho, valorizando as tecnologias leves (Ramos, 2006; Lima e Braga, 2006).

As pesquisas identificaram a EPS como uma oportunidade de "cuidar de quem cuida" no cotidiano do trabalho (Alcântara, 2015), como possibilidade de desenvolver ações de produção do cuidado com maior resolubilidade (Araújo, 2015), como fortalecimento do trabalho em equipe, do cuidado de si e do apoio matricial na Atenção Primária (Marques, 2016). Também, como uma maneira de manejar as relações na equipe e instigar a corresponsabilização do cuidado (Aiub, 2015) e a educação permanente como ferramenta para elaboração das linhas de cuidado na lógica do profissional e usuário (Lopes, 2014).

Reconhece-se a EPS como um dispositivo que permite mobilizar saberes com vistas ao cuidado integral e provocar mudanças nas relações interpessoais (entre os próprios trabalhadores das equipes, entre os trabalhadores e usuários dos serviços, entre trabalhadores e gestores). O trabalho em saúde é um trabalho vivo em ato, em que o encontro entre quem cuida e quem é cuidado, dá um sentido para a vida e também para o trabalho (Merhy, 2002). Desse modo, para que se possa produzir integralidade, a educação permanente precisa permear as práticas em saúde.

Assim, a educação pode ser empregada para transformar a prática dos trabalhadores em saúde e a EPS é entendida como um dispositivo de reflexão do fazer profissional.

\section{Considerações Finais}

Os resultados deste estudo demonstram que há um desalinhamento conceitual e operacional em torno da EPS como uma metodologia pedagógica de qualificação para o cuidado e gestão em saúde representa um dos desafios para a sua estruturação no âmbito da Atenção Básica. Com isso, ainda se identifica neste cenário, a perpetuação de atividades abalizadas em metodologia tradicional dissociada do processo de trabalho, e sem resultados no aperfeiçoamento da atenção aos usuários. 
O objeto de investigação deste estudo tem sido pesquisado na lógica de que o foco da educação permanente está no interesse de construir espaços coletivos de diálogo para a transformação das práticas e da gestão em saúde para produzir um cuidado com mais resolubilidade.

Como lacunas do conhecimento, perceberam-se a falta de estudos voltados para o monitoramento e avaliação das práticas em saúde, bem como da maior articulação entre o serviço e as instituições de ensino e a participação popular. Foi encontrado apenas um estudo a partir da percepção de gestores da Atenção Básica e um estudo que abordou o uso de recurso pedagógico (tecnológico) para favorecer a aprendizagem significativa.

Sendo assim, é de suma importância que sejam realizados outros estudos que aprofundem a avaliação acerca da educação permanente, bem como o uso de recursos didáticos/pedagógicos utilizados, tendo em vista a qualificação da gestão e do cuidado de usuários e trabalhadores.

\section{Referências}

Aiub, A C. (2015). Educação Permanente em Saúde no processo de trabalho do enfermeiro: concepções e resultados nos município de pequeno porte da DRS III- Araraquara. Dissertação (Mestrado). Escola de Enfermagem de Ribeirão Preto.São Paulo.

Alcântara, D B E. (2015). Cuidando do cuidador: um espaço potencializador de educação permanente com equipes de estratégia saúde da família.81f. Dissertação (Mestrado Profissional) - Escola Paulista de Enfermagem, Universidade Federal de São Paulo, Santos.

Almeida, J R S. (2016). A educação permanente em saúde na percepção dos profissionais da estratégia saúde da família: integração ensino-serviço na formação de profissionais do sistema único de saúde. 107 f. Tese (Doutorado em Odontologia) - Faculdade de Farmácia, Odontologia e Enfermagem, Universidade Federal do Ceará, Fortaleza.

Alves, J S. (2010). Vinculação do trabalhador ao SUS no âmbito municipal: perspectivas de valorização baseadas na educação permanente em saúde. 125 f. Dissertação (Mestrado Acadêmico em Saúde Coletiva) - Universidade Federal de Feira de Santana, Feira de Santana.

Amestoy S C, Mibrath V M, Cestari M E, \& Thofehrn M B. (2008). Educação permanente e sua inserção no trabalho da enfermagem. Cienc Cuid Saude. $7(1): 83-8$.

Bezerra A L. (2003). O contexto da educação continuada em enfermagem. São Paulo: Lemar e Martinari.

Araújo, B O. (2015). Educação permanente em saúde na estratégia saúde da família em busca da resolubilidade da produção do cuidado.207f.Dissertação (Mestrado Acadêmico em Saúde Coletiva) - Universidade Estadual de Feira de Santana, Feira de Santana.

Brasil. (2004a). Ministério da Saúde (BR). SGTES/DGEPS. Política de Educação e Desenvolvimento para o SUS: caminhos para a educação permanente em saúde - Polos de Educação Permanente em Saúde. Brasília,66 p.

Brasil (2004b). Ministério da Saúde. Portaria n. 198/GM/MS, de 13 de fevereiro de 2004. Institui a Política Nacional de Educação Permanente em Saúde como estratégia do Sistema Único de Saúde para a formação e desenvolvimento de trabalhadores para o setor e dá outras providências [Internet]. Brasília.

Brasil (2018). Ministério da Saúde. Secretaria de Gestão do Trabalho e da Educação na Saúde. Departamento de Gestão da Educação na Saúde.Política Nacional de Educação Permanente em Saúde: o que se tem produzido para o seu fortalecimento? / Ministério da Saúde, Secretaria de Gestão do Trabalho e da Educação na Saúde, Departamento de Gestão da Educação na Saúde - 1. ed. rev. - Brasília : Ministério da Saúde, 73 p. : il.

Bruno, B S. (2014). Educação permanente como dispositivo para enfrentamento dos desastres naturais: uma experiência na Região Serrana do Rio de Janeiro. 179f. Dissertação (Mestrado Profissional de Ensino na Saúde)- Escola de Enfermagem Aurora de Afonso Costa, Niterói.

Campos G W S (2006). Efeito Paidéia e o campo da saúde: reflexões sobre a relação entre o sujeito e o mundo da vida. Trabalho, Educação e Saúde; 4(1):1931 .

Campos, K F C. (2018). Educação permanente em saúde e mudança de modelo assistencial: avanços e desafios no cotidiano da atenção primária a saúde. Universidade Federal de Minas Gerais. Tese (Doutorado). Minas Gerais.

Ceccim R B. (2004). Educação permanente em saúde: desafio ambicioso e necessário. Interface (Botucatu). 9(16):161-177.

Ceccim R B. (2005). Educação permanente em saúde: descentralização e disseminação de capacidade pedagógica na saúde. Cien Saude Colet.10(4):975-986.

Ceccim, R B; \& Ferla, AA. (2008). Educação e saúde: ensino e cidadania como travessia de fronteiras. Trab. educ. saúde [online]. vol.6, n.3, pp.443-456.

Ceccim R B; \& Feuerwerker LCM (2004). O Quadrilátero da Formação para a Área da Saúde: Ensino, Gestão, Atenção e Controle Social. PHYSIS: Rev. Saúde Coletiva, Rio de Janeiro, 14(1):41- 65.

Chagas, R C. (2014). A educação permanente como prática cotidiana do trabalho em saúde. Rio de Janeiro. Dissertação [Mestrado em Saúde Coletiva] Universidade Federal Fluminense. 
Cotrim-Guimarães I M A. (2009). Programa de educação permanente e continuada da equipe de enfermagem da clínica médica do Hospital Universitário Clemente de Faria: análise e proposições. Rio de Janeiro. Dissertação [Mestrado em Saúde Pública] - Escola Nacional de Saúde Pública Sergio Arouca.

D’Avila L S, Assis L N, Melo M B, \& Brant L C. (2014). Adesão ao Programa de Educação Permanente para médicos de família de um estado da região sudeste do Brasil. Ciênc. Saúde Coletiva. 19(2):401-16.

Dias F G M, Valente G S C, Marinho M, Alves E M C, Ferreira D S, \& Rosas A M M F T (2010). A educação permanente na equipe de enfermagem para prevenir a infecção hospitalar. Rev enferm UFPE on line; [Online] 4(1):327-335

Dorneles, L L.(2017). Desenvolvimento de infográfico animado para o fortalecimento e disseminação de ações pedagógicas sobre educação permanente em saúde. 138p. Dissertação de Mestrado. Escola de Enfermagem de Ribeirão Preto/USP. Ribeirão Preto.

Duarte M L C, \& Oliveira AI. (2012). Compreensão dos coordenadores de serviços de saúde sobre educação permanente. Cogitare Enferm.17(3):506-12.

Farah B F. (2003). Educação em serviço, educação continuada, educação permanente em saúde: sinônimos ou diferentes concepções? Rev APS. 6 (2):123-5.

Fernandes, R. M. C.(2019). Educação no/do trabalho no âmbito das políticas sociais [recurso eletrônico] / organizadora Rosa Maria Castilhos Fernandes. Dados eletrônicos. Editora da UFRGS/ CEGOV. 195 p.

Figueiredo, E B L de. Educação Permanente em Saúde: inventando desformações. 115f. Dissertação (Mestrado Profissional em Ensino na Saúde)-Escola de Enfermagem Aurora de Afonso Costa, Universidade Federal Fluminense, Niterói.

Fried-Brandão, A P. (2018). Educação permanente inventiva em saúde: Um dispositivo para a reorganização da demanda odontológica em uma equipe de saúde da família. Dissertação (Mestrado Profissional em Ensino na Saúde) Escola de Enfermagem Aurora de Afonso Costa, Universidade Federal Fluminense, Niterói. Rio de Janeiro.

Lecca, C G G. (2017). Implantação e avaliação de um programa educativo conforme diretrizes da política nacional da política nacional de educação permanente em saúde. Dissertação (Mestrado) - Escola de Enfermagem da Universidade de São Paulo. São Paulo.

Lopes, V F. (2014). Percepção e prática dos profissionais da estratégia Saúde da Família sobre educação permanente em saúde: um estu do na ótica da pesquisa ação. Dissertação (Mestrado Profissional em Ensino na Saúde). Escola de Enfermagem Aurora de Afonso Costa, Universidade Federal Fluminense. Niterói. Rio de Janeiro.

Lima J C F, \& Braga I F. (2006). Projeto Memória da Educação Profissional em saúde. Anos1980-1990. Relatório final. Rio de Janeiro: Fiocruz.

Lima, S M. (2015). Educação permanente na estratégia saúde da família: um estudo de caso. Dissertação (Mestrado profissional em Ensino em Ciências da Saúde). Fundação Universidade Federal de Rondônia. Porto Velho, Rondônia.

Luz, K E S, Neto, J B L, Pinheiro, L D, \& Silvia,T A. (2020). Aplicação de metodologias ativas em núcleo de educação permanente nas organizações de saúde. Revista Eletrônica Acervo Saúde / Electronic Journal Collection Health | (48), e2832.

Macêdo, N B; Albuquerque, P C. \& Medeiros, K R. (2014). O desafio da implementação da educação permanente na gestão da educação na saúde. Trab. Educ. Saúde, Rio de Janeiro, v. 12 n. 2, p. 379-401, maio/ago. 2014.

Maciel, J A C. (2016). A Educação permanente em saúde para os cirurgiões-dentistas da estratégia saúde da família: o caso de Sobral, Ceará. 114 f. Dissertação (Mestrado em Saúde da Família) Faculdade de Medicina, Campus de Sobral, Universidade Federal do Ceará, Sobral.

Marques, E S. (2016). Educação permanente em saúde para equipes de Saúde da Família: percepções, práticas e desafios. 133 f. Dissertação (Mestrado em Enfermagem) - Escola de Enfermagem e Farmácia, Programa de Pós-Graduação em Enfermagem, Universidade Federal de Alagoas, Maceió.

Merhy E E. (2002). Saúde: a cartografia do trabalho vivo. São Paulo: Hucitec.

Morin (2002). A cabeça bem-feita: repensar a reforma, reformar o pensamento. Rio de Janeiro: Bertrand Brasil.

Minayo. (2014). O desafio o conhecimento: pesquisa qualitativa em saúde. $14^{\mathrm{a}}$ ed. São Paulo: Hucitec.

Oliveira, L S de. (2017). Problematizando as práticas profissionais de uma Unidade de Saúde da Família: o encontro dos trabalhadores. Dissertação (Mestrado Profissional)-Universidade Federal de São Paulo, Campus Baixada Santista.

Paschoal A S. (2004). O discurso do enfermeiro sobre educação permanente no grupo focal [dissertação de Mestrado em Enfermagem]. Curitiba: Universidade Federal do Paraná; 2004. $113 \mathrm{f}$.

Paschoal A S, Mantovani MF, \& Meier MJ.(2007) Percepção da educação permanente, continuada e em serviço para enfermeiros de um hospital de ensino. Rev Esc de Enferm USP. 413p): 478-484.

Pereira, A. J. (2014). Limites e possibilidades para a transformação das práticas de saúde dos trabalhadores do SUS à luz da educação permanente em saúde. Dissertação (Mestrado). Instituto Sírio Libanês de Ensino e Pesquisa. São Paulo.

Ramos M N. (2006). Referência teórico-metodológicas da educação permanente em saúde no Brasil. Rio de Janeiro: Fiocruz. Mimeografado.

Rother, E. T. (2007). Revisão sistemática x revisão narrativa. Acta Paul. Enferm, 20(2), v-vi.

Rossetti L T, Seixas C T, Castro E A B, \& Friedrich D B C. (2019). Educação permanente e gestão em saúde: a concepção dos enfermeiros. Rev Fun Care Online. jan/mar; 11(1):129-134.

Ruback, A C O. (2017). A educação permanente como uma condição para a humanização e valorização da vida no campo da saúde / Adriana Chaves de Oliveira Ruback. 123 f. Dissertação (Mestrado em Ensino) - Universidade Federal do Fluminense, Santo Antônio de Pádua. 
Research, Society and Development, v. 10, n. 5, e12010514648, 2021

(CC BY 4.0) | ISSN 2525-3409 | DOI: http://dx.doi.org/10.33448/rsd-v10i5.14648

Sena, M I C N de. (2014). Educação permanente: mediando uma aprendizagem sobre a estratégia saúde da família - um estudo piloto. 76 f. Dissertação (Mestrado em Saúde da Família) - Universidade Federal do Ceará. Faculdade de Farmácia, Odontologia e Enfermagem, Fortaleza.

Silva, J A M da. Análise das atividades educativas de trabalhadores da saúde na atenção básica: concepções de educação no trabalho, levantamento de necessidades, públixo participante e resultados esperados. São Paulo, 2009.

Saviani, D. (2008).A pedagogia no Brasil: história e teoria. Campinas: Autores Associados.

World Health Organization.(2013).Transforming and scaling up health professionals' education and training. Geneva: World Health Organization;124 p.

Terrazas, C. (2017). A educação permanente e as ações na atenção primária à saúde. Guarulhos. 2 f. Dissertação(Mestrado em Educação e Saúde na Infância e na Adolescência) - Universidade Federal de São Paulo, Escola de Filosofia, Letras e Ciências Humanas.

Vieira, A G R. (2006) V658e Educação permanente em saúde no programa saúde da família em Montes Claros : intenções, realidades e possibilidades / Alcione Gonçalves Ribeiro Vieira. - 2006

World Health Organization. (2013).Transforming and scaling up health professionals' education and training. Geneva: World Health Organization;124 p. 